\title{
REMEDIASTINOSKOPI
}

\author{
Semih HALEZEROĞLU1, Volkan BAYSUNGUR², Mertol GÖKÇE³, Gökhan ERGENE \\ ${ }^{1}$ Acıbadem Üniversitesi Tıp Fakültesi, Göğüs Cerrahisi Anabilim Dalı, İstanbul, Türkiye \\ 2Süreyyapaşa Göğüs Hastalıkları ve Göğüs Cerrahisi Eğitim ve Araştırma Hastanesi Göğüs Cerrahisi \\ Kliniği, İstanbul, Türkiye \\ ${ }^{3}$ Karaelmas üniversitesi Tıp Fakültesi Göğüs Cerrahisi Anabilim Dalı, Zonguldak, Türkiye \\ ${ }^{4}$ Şanlıurfa Eğitim ve Araştırma Hastanesi Göğüs Cerrahisi Kliniği, Urfa, Türkiye \\ e-posta: semihh@atlas.net.tr \\ doi:10.5152/tcb.2011.03
}

Mediastinal lenf bezi hastalıklarının bazı durumlarda birden çok kez histolojik olarak değerlendirilmesi gerekli olabilir. Remediastinoskopi adı verilen ikinci mediastinoskopi işlemi şu durumlarda uygulanır:

\section{REMEDIASTINOSKOPI ENDIKASYONLARI}

1. Akciğer kanserlerinde indüksiyon tedavi sonrası mediastenin yeniden evrelenmesi için

2. Bir hastada ikinci primer (metakron) bir akciğer kanserinin ortaya çıkması durumunda mediastenin bu ikinci kanser için yeniden evrelendirme intiyacı olması

3. İlk mediastinoskopi işleminin doku örneği almak açısından yetersiz kalmış olması

4. Rekürren akciğer kanserinin ortaya çıkması

5. Daha önce lenfoma, sarkoidozis veya tüberküloz gibi granülomatöz hastalıklara bağlı ortaya çıkan mediastinal lenf nodlarının tanısı için mediastinoskopi yapılmış bir hastada ortaya çıkan akciğer kanserinde bu kez mediastinal evreleme için

\section{Teknik}

Bölgenin önemli anatomik yapılar içermesi sebebiyle mediastinoskopi işleminin belli bir süre sonra tekrar yapılması ve buna ilave olarak radyoterapi ve kemoterapi gibi dokular üzerinde önemli değişiklikler oluşturan tedavilerden sonra işlemin gerçekleştirilmesi beraberinde önemli operatif güçlükler getirir. Bu nedenle remediastinoskopi işlemi sadece bu teknik hakkında tecrübesi olan cerrahlar tarafından gerçekleştirilmelidir.
İşleme ait teknik detaylar şöyledir:

1. Remediastinoskopi radyoterapi tamamlandıktan 4 hafta sonra yapılmalıdır.

2. Videomediastinoskop daha geniş olduğundan normal çaplı klasik mediastinoskop kullanılmalıdır.

3. Hasta supin pozisyonda iken, endotrakeal entübasyonla genel anestezi altında önceki mediastinoskopi transvers skarı üzerinden yapılır.

4. Genellikle bölgedeki adaleler fibrotik bir yapıya dönüşmüş olduğunda keskin diseksiyonla pretrakeal alana yaklaşılır.

5. İnnominate arter trakeaya çok yapışık olabilir ve bu durum çok tehlikelidir. Bu nedenle pretrakeal plan genellikle güvenli bir şekilde bulunamaz. Olguların çoğunda sol paratrakeal hat üzerinde künt diseksiyon ile tünel oluşturularak mediastene girilir ve mediastinoskop yerleştirilir.

6. Arkus aortanın altından aspiratör yardımıyla künt diseksiyon devam edilerek subkarinal lenf nodlarına ulaşılır.

7. Sol ve sağ paratrakeal ve subkarinal lenf nodlarından biyopsiler alınır, lenf nodu biyopsilerinden olan kanamalar elektro-koagülasyon (koter) ve tampon koyularak tedavi edilir.

\section{SONUÇLAR VE KOMPLIKASYONLAR}

\section{Komplikasyonlar}

Remediastinoskopi komplikasyonları göreceli olarak yüksek bir yöntem olarak bilinir. Ancak, literatürde bildirilen mortalite oranı son derece düşüktür ve 2002- 
2007 yılları arasında altı ayrı seride toplam 370 hasta içerisinde 1 mortalite görülmüştür (1-6). Bu mortalitenin de işlemin kendisinden çok hasta seçimindeki bir eksiklik nedeniyle olduğu ifade edilmiştir. Morbidite oranı ise yine bu 370 hasta içeren 6 ayrı seride $\% 0-3.9$ arasında bildirilmiştir (Tablo 1).

Dikkat edilmelidir ki, literatürde bildirilen remediastinoskopi olgu sayıları çok yüksek değildir. Bu yöntemi şiddetle savunan yazarlar dahi yılda sadece birkaç adet remediastinoskopi işlemi gerçekleştirmektedirler. Düşük komplikasyon oranlarının işlemin sık olarak yapıldığı merkezlere ve tecrübeli cerrahlara ait sonuçlar olduğu da aynı şekilde akılda tutulmalıdır.

\section{Sonuçlar}

Farklı serilerde ortaya çıkan sonuçlar Tablo 2'de verilmiştir.

Tablo 2'den anlaşılacağı üzere remediastinoskopi ile elde edilen sonuçlar standart servikal mediastinoskopiye göre daha düşüktür. Özellikle yalancı negatiflik değerleri yüksektir. Bu nedenle, remediastinoskopi ile elde edilen negatif sonuçlar mutlaka PET-CT sonuçları ile birlikte değerlendirilmeli ve PET pozitif hastalarda ortaya çıkan negatif remediastinoskopi sonuçları mümkünse EBUS, EUS gibi yöntemlerle tekrar değerlendirilmelidir.

\section{AKCIĞER KANSERINDE INDÜKSIYON TEDAVi SONRASINDA REMEDIASTINOSKOPI ILE YENIDEN EVRELEME}

Bütün endikasyonları içerisinde remediastinoskopi en sık olarak KHDAK hastalarında indüksiyon tedavi sonrasında mediastenin yeniden evrelendirilmesinde kullanılır. Ancak, hem işlemin teknik olarak içerdiği zorluklar hem sonuçları konusunda mevcut farklı değerler hem de günümüzde hızla gelişen diğer daha az invaziv yöntemlerin mevcut olması sebepleriyle bu işlem üzerinde oldukça fazla tartışma mevcuttur.

\section{KHDAK'de İndüksiyon Tedavisinin Rolü}

Remediastinoskopinin en sık uygulandığı KHDAK'li hastalarda indüksiyon tedavisi ise diğer önemli bir tartışma konusudur. 2007 yılında yayımlanan ikinci basım ACCP akciğer kanseri tedavi rehberinde "bir çalısma protokolü içerisinde olanlar hariç olmak üzere, N2 hastalık durumunda indüksiyon tedavisi sonrası cerrahi girişim önerilmez" ifadesi yer alır (11). Benzer şekilde North American Lung Cancer Intergroup 2006 yılı faz III çalışması (12) ve European Organisation for Research and Treatment of Cancer-Lung Cancer Group 2007 yılı randomize kontrollü çalışması (13) sonuçlarında sadece kemoradyoterapi alan hastalarla indüksiyon kemoradyoterapisi sonrası cerrahi uygulanan hastaların

\begin{tabular}{|c|c|c|c|c|c|c|c|c|}
\hline Yazar, yıl & Ref. & $\mathbf{n}$ & іт & $\begin{array}{c}\text { Morbidite } \\
\text { (\%) }\end{array}$ & $\begin{array}{c}\text { Mortalite } \\
\text { (\%) }\end{array}$ & $\begin{array}{c}\text { Sensitivite } \\
(\%)\end{array}$ & $\begin{array}{c}\text { Spesifisite } \\
(\%)\end{array}$ & $\begin{array}{c}\text { Kesinlik } \\
(\%)\end{array}$ \\
\hline Pitz, 2002 & [1] & 15 & $\mathrm{KT}$ & 0 & 0 & 71.4 & 100 & 87 \\
\hline Rami-Porta, 2003a & [2] & 24 & KT & 0 & 0 & 83 & 100 & 91 \\
\hline Stamatis, 2005 & [3] & 165 & KT-RT & 2.5 & 0 & 74 & 100 & 93 \\
\hline De Waele, 2006 & [4] & 32 & KT $(n=26) K T-R T(n=6)$ & 3.1 & 0 & 71 & 100 & 84 \\
\hline De Leyn, 2006 & [5] & 30 & CT & 0 & 0 & 29 & 100 & 60 \\
\hline De Waele, 2007b & [6] & 104 & CT $(n=79)$ CT-RT $(n=25)$ & 3.9 & 1 & 70 & 100 & 80 \\
\hline
\end{tabular}

Tablo 2. Remediastinoskopi sonuçları

\begin{tabular}{|lcccc|}
\hline & De Vaele (4) & Marra. (8) & Herth (9) & Cerfolio (10) \\
\hline Gerçek Pozitif & 40 & 20 & 89 & 21 \\
Gerçek Negatif & 47 & 71 & 7 & 52 \\
Yalancı Pozitif & 0 & 0 & 0 & 7 \\
Yalancı Negatif & 17 & 13 & 28 & 13 \\
Toplam & 104 & 104 & 124 & 93 \\
Sensitivite & 0.65 & 0.52 & 0.74 & 0.50 \\
Negatif Prediktif Değer & 0.69 & 0.81 & 0.13 & 0.50 \\
\hline
\end{tabular}


yaşam sürelerinde hiçbir anlamlı fark ortaya çıkmadığı bildirilmiştir. Yine de indüksiyon tedavisi uygulanmış hastalarda mediastinal lenf nodlarında negatifleşme sağlanan grubun negatifleşme sağlanmayan gruba göre daha uzun bir beklenen yaşam süresine sahip olduğunu gösteren çalışmaların varlığı da göz önünde bulundurularak (14), bir bilimsel çalışma protokolü içerisinde yer almak şartıyla indüksiyon tedavisi uygulanmış olan hastalarda cerrahi girişim uygulanması planlandığında bunun öncesinde mediastinal lenf nodlarının patolojik olarak yeniden evrelendirilmesi tıbbi bir zorunluluk olarak ortaya çıkmaktadır.

Remediastinoskopi ile elde edilen sonuçların yaşam süresi üzerine etkileri De Waele ve arkadaşlarının Şekil 1'de gösterdiği gibi son derece anlamlıdır (15). Remediastinoskopinin gerçek pozitif olduğu hastaların beklenen yaşam süreleri mediasten lenf nodlarında gerçek negatiflik olanlara göre belirgin şekilde düşüktür. Bu durum yaşam süresinin kısıtlı olduğu mediasten pozitif hastalarda remediastinoskopinin gereksiz bir cerrahi girişimi önlemedeki önemli rolünü açık şekilde ortaya koymaktadır.

\section{YENIDEN EVRELENDIRMEDE REMEDIASTINOSKOPI DIŞINDAKI DIĞER ALTERNATIFLER NELERDIR?}

İndüksiyon tedavisinin etkinliği kanıtlanmış bir yöntem olmadığını ve remediastinoskopinin teknik zorluk-

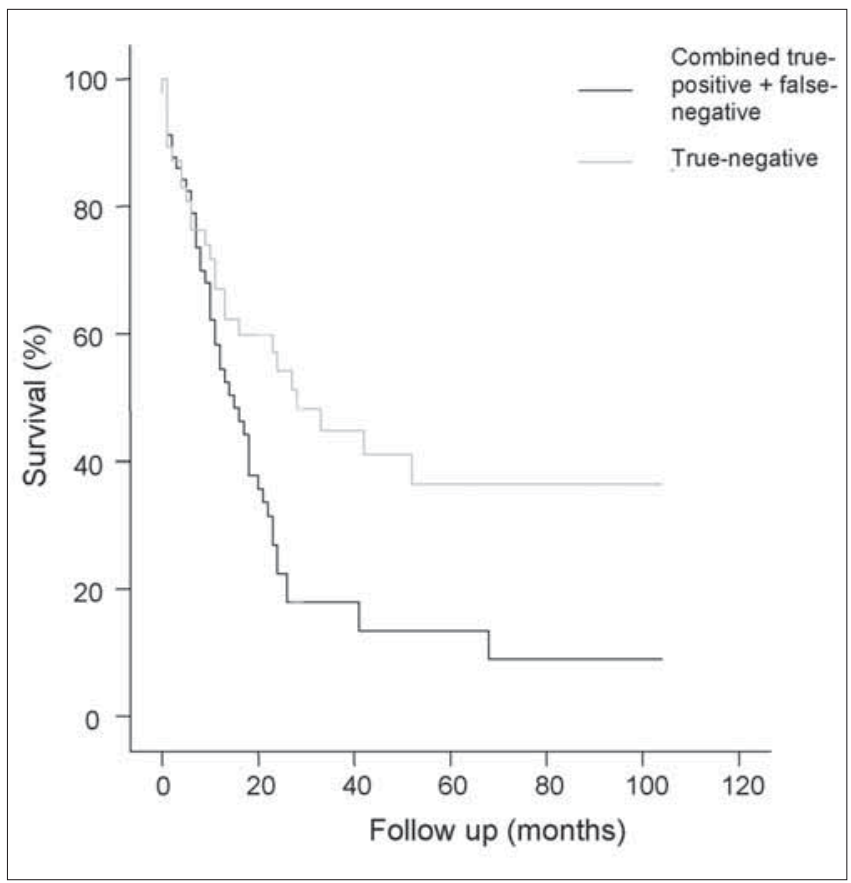

Şekil 1. Remediastinoskopi sonuçlarının yaşam süresi üzerine etkisi (15 no'lu kaynaktan alınmıştır) larını, sonuçlarının mükemmel olmadığını ve nispeten yüksek komplikasyon oranlarına sahip olduğunu bildiğimize göre, diğer non-invaziv (PET-CT gibi), daha az invaziv (transbronşiyal lenf nodu aspirasyonu, VATS ve EBUS gibi) veya daha ileri (TEMLA gibi) yöntemlerin yeniden evrelendirmedeki etkinlik durumlarını incelemekte fayda vardır.

\section{PET-CT ile yeniden evreleme}

PET-CT'nin indüksiyon tedavisi sonrası mediastenin yeniden evrelendirilmesindeki rolü kesinlik kazanmış değildir. Bu konuda ortaya çıkan en önemli ortak inanış PET-CT'de negatif görülen nodların inandırıcılığının yüksek olmayışından kaynaklanır (düşük negatif prediktif değer!).

A. 2004 yılında Vansteenkiste ve arkadaşlarınca Lancet Oncology dergisinde yayınlanan bir konu hakkındaki tıbbi literatürün "sistematik gözden geçirilmesi - review" sonucuna göre indüksiyon tedavisi sonrası pozitif veya negatif sonuçlara göre cerrahi uygulama veya cerrahiden kaçınma konusunda PET-CT'nin güvenilir bir yöntem olmadığı belirtilmiştir (16).

B. Leuven Akciğer Kanseri Grubu'nun 2006 yılında yayınlanmış prospektif çalışmalarının sonucu ise bundan bir ölçüde farklıdır (5). Bu çalışmada PET-CT'nin pozitif prediktif değerinin yüksek oluşu sebebiyle pozitif PET-CT sonucu olanlarda operabiliteye karar vermekte PET-CT'nin kullanılabileceğini ve PET-CT'nin tanı değerinin mediastinoskopiye göre anlamlı derecede yüksek olduğu sonucuna varılmıştır. Ancak, burada altı çizilmesi gereken önemli bir nokta bu çalışmada remediastinoskopi işleminin klasik mediastinoskop ile değil videomediastinoskop ile yapılmış olması dolayısıyla sonuçların daha kötü olarak ortaya çıkmış olmasıdır. Videomediastinoskopun çapının daha geniş olması zaten teknik olarak önemli güçlükleri olan remediastinoskopi işlemini daha da güçleştirmekte ve dolayısıyla sonuçlarını da olumsuz şekilde etkilemektedir.

C. Cerfolio ve arkadaşlarınca yapılmış olan çalışma sonucu ise PET-CT ile yeniden değerlendirmede SUV değerlerinin kullanılması ile ilgilidir (10). Indüksiyon tedavisi sonrası SUV değeri \%50 ve daha fazla şekilde azalmışsa bu durumun gerçek negatifleşme anlamına geleceği ancak bu oranda bir SUV gerilemesi sağlanamamış olmasının gerçek pozitiflik anlamına gelmeyeceği ve bu nodlardan biyopsi alınması gerektiği vurgulanmıştır. 


\section{Transbronşiyal İğne Aspirasyonu (TBIA) ile Yeniden Evreleme}

Kunst ve arkadaşlarının 2007 yılında yayınlamış oldukları çalışmada 14 hastada elde ettikleri sonuçlara dayanarak TBIA'nun indüksiyon tedavisi sonrası cerrahi uygulamaya aday olan hastalarda mediastenin yeniden evrelendirilmesinde başlangıç inceleme yöntemi olması gerektiğini öne sürmüşlerdir (17). İşlemin kolay uygulanabilir olması, EBUS gibi özellikli bir endoskopi sistemine intiyaç olmayışı ve düşük invaziv karakteri, maliyeti ve komplikasyon oranı göz önüne alındığında mediastenin yeniden değerlendirme işleminde gerçekten de ilk aşama işlem olarak önerilmesi gerekir. Ancak bu işleme ait çok sayıda yayınlanmış bilimsel kanıt mevcut değildir.

\section{VATS ile yeniden evreleme}

$\mathrm{Bu}$ konuda yapılmış en önemli çalışma CALBG 39803 faz II çalışmasıdır (18). On ayrı merkezden 70 hasta üzerinde yapılan çalışma sonucuna göre VATS'ın yeniden evreleme için uygun bir yöntem olduğu vurgulanmıştır. Avantajı mediastinal lenf nodlarından mediastinoskopun ulaşamayacağı alanları da inceleme olanağına sahip olması (8, 9 ve 10 no'lu istasyonlar gibi), plevral metastazların tespiti ve $T$ evresi hakkında daha objektif veriler sağlamasıdır. Bununla birlikte N3 nodların tespit edilememesi gibi önemli bir eksik yönü mevcuttur.

\section{EBUS ile Yeniden Evreleme}

İndüksiyon tedavi sonrası EBUS ile mediastenin yeniden evrelendirilmesi konusunda birçok çalışma yapılmış ve tamamı bu işlemin düşük invaziv karakteri ve olumlu sonuçları ile son derece güvenli bir yöntem olduğunu ortaya koymuştur. Remediastinoskopi işleminin yerini alma konusunda en önemli alternatif olan bu yöntem için 2010 yılında yayınlanan bir çalışmada bilateral EBUS lenf nodu biyopsi sonuçları transservikal bilateral genişletilmiş mediastinal lenfadenektomi (TEMLA) ile elde edilen sonuçlar ile karşılaştırıldığında EBUS ile ortaya çıkan yalancı negatifliğin sadece \%12 olduğu bunun da sadece büyük çapı $7.5 \mathrm{~mm}$ 'den daha kısa ola lenf nodlarında ortaya çıktığı belirtilmiştir (19). Araştırmacılar bu sonuçlar ile, negatif EBUS için daha ileri bir teknik ile yeniden evrelemeye gerek olmadığını ileri sürmüşlerdir. Halen hızla artmakta ise de EBUS ekipmanı sayısı ve tecrübenin yeterli olmayışı işlemin eksik yönünü oluşturmaktadır.

\section{Indüksiyon tedavi sonrası transservikal bilateral genişletilmiş mediastinal lenfadenektomi (TEMLA) ile yeniden evreleme}

Mayıs 2010 tarihinde Zielinski ve arkadaşları (20) KHDAK'li hastalarda indüksiyon tedavi sonrası TEMLA ile mediastenin yeniden evrelendirilmesine ait sonuçları yayınladı. Elde edilen verilerin standart remediastinoskopi ile karşılaştırılmasında ortaya çıkan sonuçlar TEMLA yönünden o derece yüksekti ki (\%83'lük bir sensitivite değeri ve \%93'lük bir negatif perdiktif değer!) aynı dergide bu konu ile ilgili editöryel yorum yazısının başlığı "Mediastinal yeniden evreleme: kutsal kase bulundu mu?" şeklindeydi (21).

TEMLA ileri bir cerrahi yöntemdir ve halen bütün dünyada çok az merkez tarafından uygulanmaktadır. Yukarıda belirtilen çalışmada TEMLA yapılan hastaların çok az bir kısmında indüksiyon tedavisi öncesinde mediastinoskopi yapılmış olması bu yöntemin remediastinoskopi ile karşılaştırılmasını güç hale getirmektedir. Yine de elde edilen sonuçlar diğer tüm yeniden değerlendirme yöntemlerine göre belirgin şekilde daha iyidir. Ancak, elimizde daha az invaziv yöntemlerin varlığında TEMLA uygulanması konusunda tereddütlerin olması da kaçınılmazdır.

\section{SONUÇLAR}

1. KHDAK'li hastalarda indüksiyon tedavisi sonrası cerrahi uygulamanın standart bir tedavi yöntemi olmadığı ve indüksiyon tedavisi sonrası cerrahi tedaviden fayda görmesi olası grubun sadece mediastinal lenf nodları negatifleşmiş olan hasta grubunun olduğu dikkate alınarak mediastenin yeniden evrelendirilmesinde remediastinoskopinin yanı sıra PET-CT, TBIA, EBUS ve VATS gibi yöntemlerin de kullanılabileceği bilinmelidir.

2. Remediastinoskopi teknik olarak güç bir yöntem olsa da komplikasyon oranları işlemin tecrübeli ekiplerce gerçekleştirildiği durumlarda çok yüksek değildir.

3. İndüksiyon tedavisi planlanan bir hastada mediastenin ilk değerlendirmesinin EBUS ile yapılması durumunda yeniden değerlendirmede mediastinoskopinin kullanılması hem işlemi kolaylaştırır hem de remediastinoskopiye göre daha iyi sonuçlar elde edilebilir. Bu nedenle, KHDAK'li bir hastada ilk değerlendirmeyi daha az invaziv bir yöntemle gerçekleştirerek mediastinoskopiyi yeniden evrelendirmede kullanmak önerilir (ESTS rehberi, kaynak 22, ACCP rehberi, kaynak 23, EORTC 08981 çalışması, kaynak 24).

\section{KAYNAKLAR}

1. Pitz CC, Maas KW, van Swieten HA, de la Riviere AB, Hofman $\mathrm{P}$, Schramel FM. Surgery as part of combined moda- 
lity treatment in stage IIIB non-small cell lung cancer. Ann Thorac Surg 2002; 74: 164-9. [CrossRef]

2. Rami-Porta $R$, Mateu-Navarro $M$, Serra-Mitjans $M$, Hernandez-Rodriguez $\mathrm{H}$. Remediastinoscopy: comments and updated results. Lung Cancer 2003; 42: 363-4. [CrossRef]

3. Stamatis G, Fechner S, Hillejan L, Hinterthaner M, Krbek T. Repeat mediastinoscopy as a restaging procedure. Pneumologie 2005; 59: 862-6. [CrossRef]

4. De Waele M, Hendriks J, Lauwers P et al. Nodal status at repeat mediastinoscopy determines survival in non-small cell lung cancer with mediastinal nodal involvement, treated by induction therapy. Eur J Cardiothorac Surg 2006; 29: 240-3. [CrossRef]

5. De Leyn P, Stoobants S, De Wever W et al. Prospective comparative study of integrated PET-CT compared with remediastinoscopy in the assessment of residual mediastinal lymph node disease after induction chemotherapy for mediastinoscopy-proven stage IIIA-N2 non-small cell lung cancer: a Leuven Lung Cancer Group Study. J Clin Oncol 2006; 24: 333-9. [CrossRef]

6. De Waele M, Serra-Mitjans M, Hendriks $J$ et al. Accuracy and survival of repeat mediastinoscopy (reMS) after induction therapy for non-small cell lung cancer (NSCLC) in a combined series of 104 patients. Interact Cardiovasc Thorac Surg 2007; 6: S252.

7. Paul E. Van Schil and Michèle De Waele. A second mediastinoscopy: how to decide and how to do it? Eur. J. Cardiothorac. Surg., April 2008; 33: 703-6.

8. Marra A, Hillejan L, Fechner S, Stamatis G. Remediastinoscopy in restaging of lung cancer after induction therapy. J Thorac Cardiovasc Surg 2008; 135: 843-9. [CrossRef]

9. Herth FJ, Annema JT, Eberhardt R et al. Endobronchial ultrasound with transbronchial needle aspiration for restaging the mediastinum in lung cancer. J Clin Oncol 2008; 26: 3346-50. [CrossRef]

10. Cerfolio RJ, Bryant AS, Ojha B. Restaging patients with N2 (stage IIla) non-small cell lung cancer after neoadjuvant chemoradiotherapy: a prospective study. J Thorac Cardiovasc Surg 2006; 131: 1229-35. [CrossRef]

11. Robinson LA, Ruckdeschel JC, Wagner H, Stevens CW. Treatment of non-small cell lung cancer-stage IIIA: ACCP evidence-based clinical practice guidelines (2nd edition). Chest. 2007; 132: 243S-65S. [CrossRef]

12. van Meerbeeck JP, Kramer GW, Van Schil PE et al. European Organisation for Research and Treatment of CancerLung Cancer Group. Randomized controlled trial of resection versus radiotherapy after induction chemotherapy in stage IIIA-N2 non-smallcell lung cancer. J Natl Cancer Inst 2007; 99: 442-50.

13. North American Lung Cancer Intergroup. Phase III study of concurrent chemotherapy and radiotherapy (CT/RT) versus CT/RT followed by surgical resection for stage IIIA (pN2) nonsmall cell lung cancer (NSCLC): outcomes update of North American Intergroup 0139 (RTOG 9309). Oncologist 2006; 11: 43.

14. Detterbeck FC, Socinski MA. Induction therapy and surgery for I-IIIA, B non-small cell lung cancer. In: Detterbeck FC, Socinski MA, Rivera MP, Rosenman JG (Eds.), Diagnosis and Treatment of Lung Cancer. An Evidence-based Guide for the Practicing Clinician. Philadelphia: WB Saunders, 2001; 267-82.

15. De Waele M, Serra-Mitjans M, Hendriks $\mathrm{J}$ et al. Accuracy and survival of repeat mediastinoscopy after induction therapy for non-small cell lung cancer in a combined series of 104 patients. Eur. J. Cardiothorac. Surg. May 2008; 33: 824-8. [CrossRef]

16. Vansteenkiste J, Fischer BM, Dooms C, Mortensen J. Positron-emission tomography in prognostic and therapeutic assessment of lung cancer: Systematic review. Lancet Oncol 2004; 5: 531-40. [CrossRef]

17. Kunst PW, Lee P, Paul MA, Senan S, Smit EF. Restaging of mediastinal nodes with transbronchial needle aspiration after induction chemoradiation for locally advanced non-small cell lung cancer.J Thorac Oncol. 2007; 2: 912-5. [CrossRef]

18. Jaklitsch MT. Prospective phase II trial of pre-resection thoracoscopic (VATS) restaging following neoadjuvant therapy for IIIA-N2 NSCLC: results of CALGB 39803. J Clin Oncol 2005; 23: 636s.

19. Szlubowski A, Herth FJF, Soja J et al. Endobronchial ultrasound-guided needle aspiration in non-small-cell lung cancer restaging verified by the transcervical bilateral extended mediastinal lymphadenectomy-a prospective study Eur. J. Cardiothorac. Surg, May 2010; 37: 1180-4. [CrossRef]

20. Zielinski M, Hauer L, Hauer J, Nabialek T, Szlubowski A, and Pankowski J. Non-small-cell lung cancer restaging with transcervical extended mediastinal lymphadenectomy. Eur. J. Cardiothorac. Surg. April 2010; 37: 776-80. [CrossRef]

21. Van Schil PE, Hendriks JMH, De Waele M, and Lauwers $P$ Editorial comment: Mediastinal restaging: has the Holy Grail been found? Eur. J. Cardiothorac. Surg. April 2010; 37: 780-1. [CrossRef]

22. De Leyn $P$, Lardinois D, Van Schil $P$ et al. ESTS European trends in preoperative and intra-operative nodal staging: ESTS guidelines. J Thorac Oncol 2007; 2: 357-61. [CrossRef]

23. Detterbeck FC, Jantz MA, Wallace M, Vansteenkiste J, Silvestri GA. Invasive mediastinal staging of lung cancer. ACCP evidence-based clinical practice guidelines. Chest 2007; 132: 202S-20S. [CrossRef]

24. Surmont V, van Klaveren RJ, Goor C et al. Lessons to learn from EORTC study 08981: a feasibility study of induction chemoradiotherapy followed by surgical resection for stage IIIB non-small cell lung cancer. Lung cancer 2007; 55: 95-9. [CrossRef] 